\title{
Unauthorized Vehicle Parking Detection and Auto-Locking using an Arduino and a Relay
}

\author{
C. George Christopher, J. Vidhya
}

\begin{abstract}
As the populace expands step by step, the quantity of vehicles are additionally expanding and this prompts numerous mishaps and traffic clogs. In this bustling world, individuals consistently use to leave vehicles at confined or no parking zones. At the point when a vehicle has been left at no parking territory, the street gets smaller and cause traffic clog. Enormous number of traffic police are sent to check the unlawful stopping and fine the proprietors with the goal that they would not stop again in no stopping zone, yet it is anything but a successful arrangement. In this manner, different advancements have been utilized for the identification of vehicles that are left at no leaving zone. In this proposed framework, vehicles which are parked at restricted area is being detected and locked using a relay.
\end{abstract}

Keywords: Confined-parking, Traffic Clogs, Detection Methods, and Locking System.

\section{INTRODUCTION}

$\mathrm{T}$ he parking contravention is the activity of parking the vehicle in the unapproved spot or parking in a limited territory. The current circumstance in significant towns and urban areas is the regularly developing human inhabitants just as the quantity of vehicles. This makes the ascent and requirement for staggered stopping spaces. Free-stopping is the most predominant type of stopping in India. In the event that the individuals wanted to stop on the roadside yet there are no empty places, the individuals drive around chasing for the spot. Particularly in the metropolitan zone this issue raises in view of the enormous number of vehicles with not very many the measure of the parking spot.

In this new period, present-day innovation has improved the arrangement of living and with a legitimate utilization of innovation, it is conceivable to fabricate an existence where everything can be practiced all the more effectively with the help of innovation. Vehicle leaving the board requires robotization like some other field to guarantee security and solace. With the immense development of populace and expanding measure of vehicles it has turned out to be hard to discover adequate space for vehicle leaving in open spots.

Revised Manuscript Received on December 30, 2019.

* Correspondence Author

C. George Christopher, PG scholar, Department of Electronics and Communication Engineering, IFET College of Engineering, Villupuram (Tamilnadu) India. E-mail: georgechristopher007@gmail.com

J. Vidhya, Associate Professor, Department of Electronics and Communication Engineering, IFET College of Engineering, Villupuram (Tamilnadu) India. Email: vidhyaja@gmail.com

(C) The Authors. Published by Blue Eyes Intelligence Engineering and Sciences Publication (BEIESP). This is an open access article under the CC BY-NC-ND license (http://creativecommons.org/licenses/by-nc-nd/4.0/)
This doesn't just waste our vitality yet in addition lose our important time. Along these lines, the idea of mechanized vehicle leaving framework and unapproved leaving identifier has been a need for some time. In this paper, we proposed a model that can detect the vehicles at unauthorized or restricted zone and also locking mechanism is done to the vehicle.

This paper has organized as follows. In section II, literature survey of this parking detection and control measures are presented. In section III, proposed method with block diagrams and hardware software requirements are presented. In section IV, result and implementation of this system is described. Final conclusion and future enhancement are presented in section V and VI respectively.

\section{LITERATURE SURVEY}

As indicated by this study, different discoveries and the innovations are utilized for unapproved vehicle parking detection and control apportions are conveyed.

Saifa Khantasak, et.al [1] proposed a system does video processing technique, begins with getting the first frame picture and storing it as the fixed background image. The pixels of the present picture are extracted as the foreground by thresholding the distinction between the fixed background picture and the current frame picture. Another kind of background used is a changeable background image. This changeable background image is updated for every 50 frames. Then the three-frame difference technique is utilized to discover the moving object region. This three-frame difference is acquired from the difference of the input video sequence with fixed background, and with the changeable background. Then, the framework utilizes the intersect operation of two differential outcomes in order to shrink foreground aperture due to the vehicle's speed and the frame rate.

Sanam Kazi, et.al [2] exhibited a thought of a booking based stopping framework to maintain a strategic distance from traffic clog. The framework will control the drivers to the appointed stopping goal and the driver can stop at the allocated space without scanning for a stopping opening. GPS method is used for helping the driver to distinguish the nearest leaving region to the vehicle. Graphical picture will be appeared to the driver which shows the accessible and saved stopping openings so it will help the drivers for choosing the reasonable stopping space. In the event that as far as possible surpasses the given time, the notice will be sent to the driver.

Adil Hilmani, et.al [3] exhibited the structure and advancement of a shrewd stopping framework utilizing something like date innovations utilizing remote sensor system. 
This framework used a flexible and blend of a self-association process for remote sensor organizes that acclimates to a wide scope of vehicle leaving framework present in the city and offered an unrivalled overseeing of the vitality utilization during the remote correspondence to extend the life expectancy of the sensor centre points.

This structure additionally offered creative offices which encourage the undertaking to the drivers when looking for an open parking space in the city close to their goal, in a snappy and capable way.

Karthika.K.B, et.al [4] displayed a framework that uses the RFID tag, which contains a unique code in it. The RFID pursuer is used to peruse the transmitted ID and if the individual id doesn't facilitate, by then thusly the ready data will be sent to the proprietor by the SMS notice. This is an inventive electronic stopping installment framework. This is used to deliver an answer for the districts, and the private parking structure proprietors. By using the RFID innovation the explanation has been conveyed for experienced issues in the parking garage the board framework.

Bhenesha Shree, et.al [5] exhibited a framework, where the circuit uses RFID pursuer to check the RFID tag and the information is sent to the microcontroller. After the ID is perused, Microcontroller checks whether the name ID matches or not. On the off chance that the ID is composed, LCD shows the string "ID is coordinated" on the LCD show and the engine development demonstrates the opening and closing of entryways. The motors are worked dependent on the $\mathrm{H}$ extension circuit. They keep up a relentless voltage over the circuit and keep the circuit from getting harm. The clockwise turn sees the opening of out though the anticlockwise turn sees the finishing off.

From the above literature, it is obvious that thorough research has been as of now done by different scientists utilizing different advancements for the discovery of illicit leaving vehicles and control measures. There is no framework accessible for auto-bolting the vehicle, on the off chance that it is left at unapproved zone.

\section{PROPOSED SYSTEM}

In the proposed method (Fig. 1), the RFID pursuer needs to set under the vehicle which is associated with an Arduino UNO and RFID labels ought to be mounted out and about at no leaving zones. In the event that a vehicle is left in a zone where the leaving is restricted, RFID transmitter which is set under the vehicle arrives in a scope of the RFID label which is mounted out and about. When this occurs, the RFID pursuer peruses the transmitter ID and presentations an admonition message on the vehicle's dashboard show utilizing the Arduino which is customized for it and the framework furnishes 60 seconds commencement with consistent notice to the driver utilizing the bell and red light in dashboard. In any case, if the vehicle proprietor doesn't move the vehicle following 60 seconds of commencement, the locking component will be enacted by terminating the power supply to the vehicle's motor utilizing a relay (refer fig. 2 for flow of this process).

At that point the traffic police show up and discharge the vehicle in the wake of getting the punishment sum.

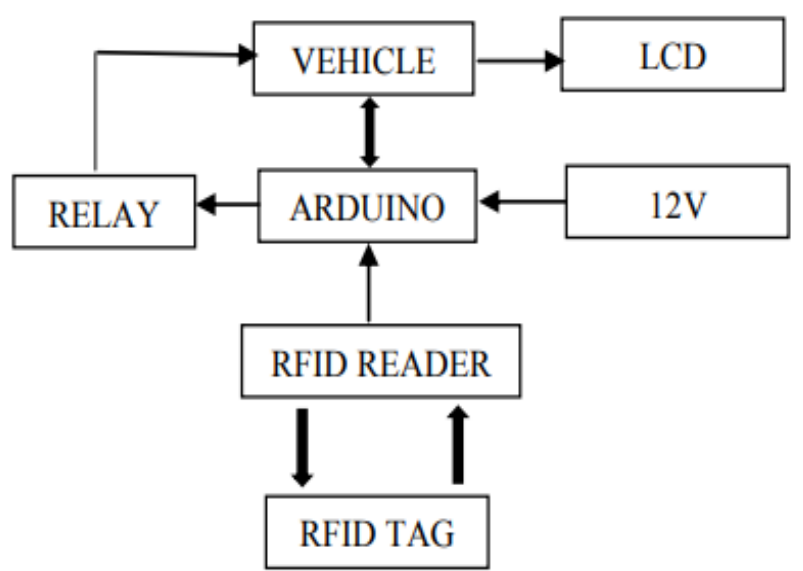

Fig.1 Proposed block diagram for unauthorized vehicle parking detection and locking mechanism

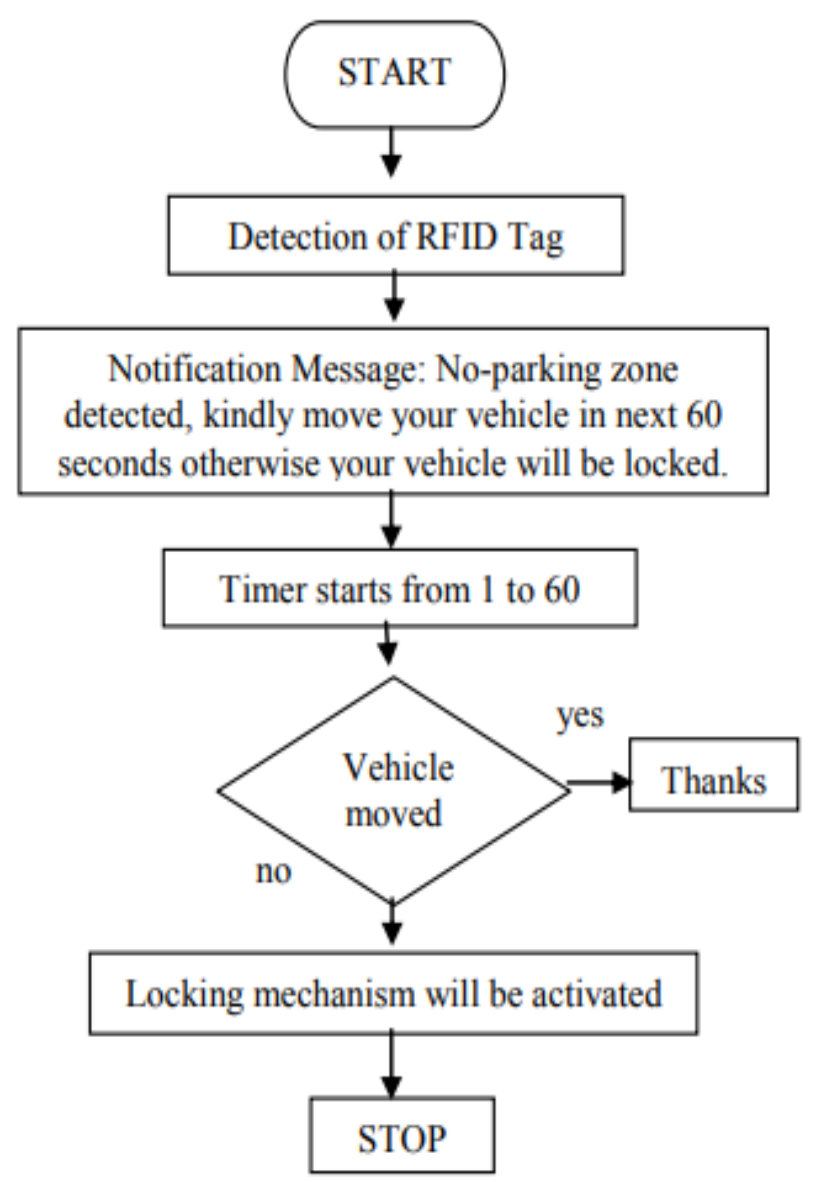

Fig.2 Flow diagram for the proposed system

The above drawn flow diagram (fig.2) describes the operation of the proposed model, where it starts by detecting the RFID tag and continues by sending a warning notification and 60 seconds countdown. If the vehicle doesn't move within the given time, locking mechanism will be activated. 


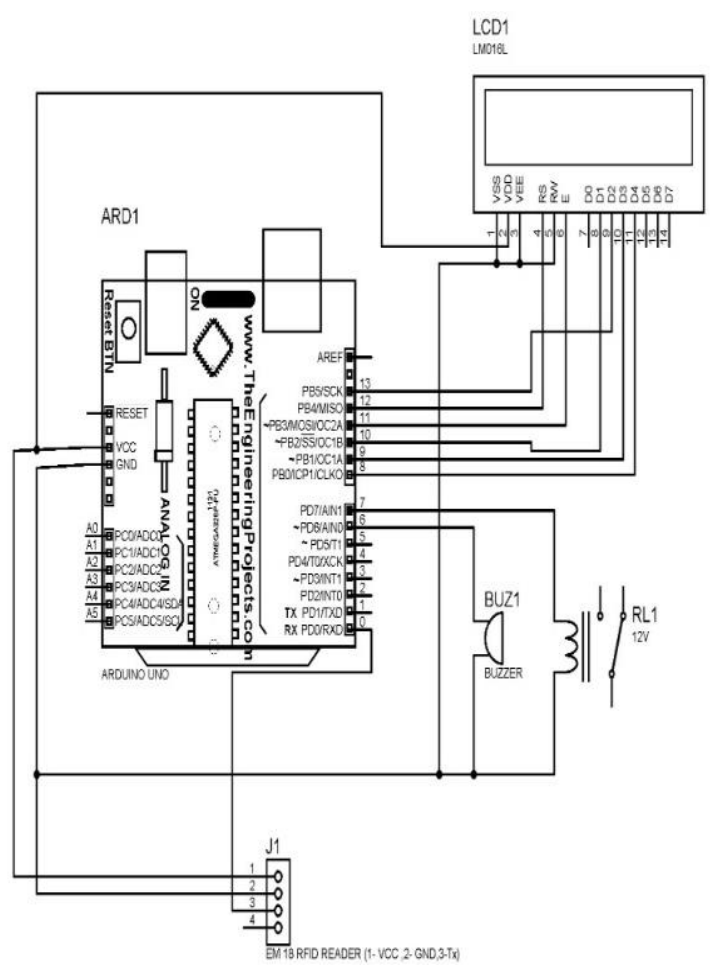

Fig.3 Circuit Diagram

Circuit diagram (Fig.3) clearly shows the connections between the Arduino UNO and the other components which are LCD display, Buzzer, RFID reader and a Relay. RFID module sends the signal to arduino using TX pin which will be connected to RX pin in the arduino. Pin no.5 and 7 is assigned as input to the relay and the buzzer from the arduino. $16 \mathrm{x} 2 \mathrm{LCD}$ display is connected to the arduino at pin no.J1 to J16 respectively.

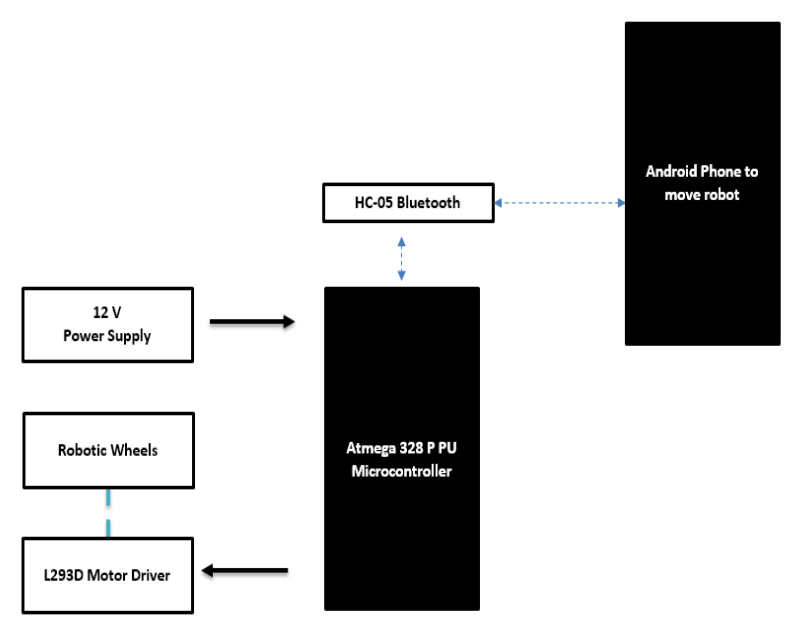

Fig.4 Car robot model

The car robot model (Fig.4) consist of Arduino nano connected to a motor driver where $12 \mathrm{~V}$ power supply is given to it. The arduino nano has to be programmed for the movement of the vehicle model. This car robot is controlled by using an android mobile phone by interfacing a Bluetooth module in arduino nano. The robotic wheels will be rotated according to the instruction given by the android mobile. This system is used in the proposed model to demonstrate the locking mechanism by terminating the power supply to the motor driver using the relay.

\section{Hardware Requirements}

a) Arduino UNO board
The Arduino Uno (Fig. 5) is a microcontroller board dependent on the microchip ATmega328P microcontroller. The board is outfitted with sets of advanced and simple info/yield sticks that may be interfaced with different extension boards and different circuits. The board has 14 computerized pins, 6 simple pins, and programmable with the Arduino IDE by means of a USB cable. It tends to be organized by the USB cable or by a 9-volt battery, however it grants voltages around in the range of 7 and 20 volts.

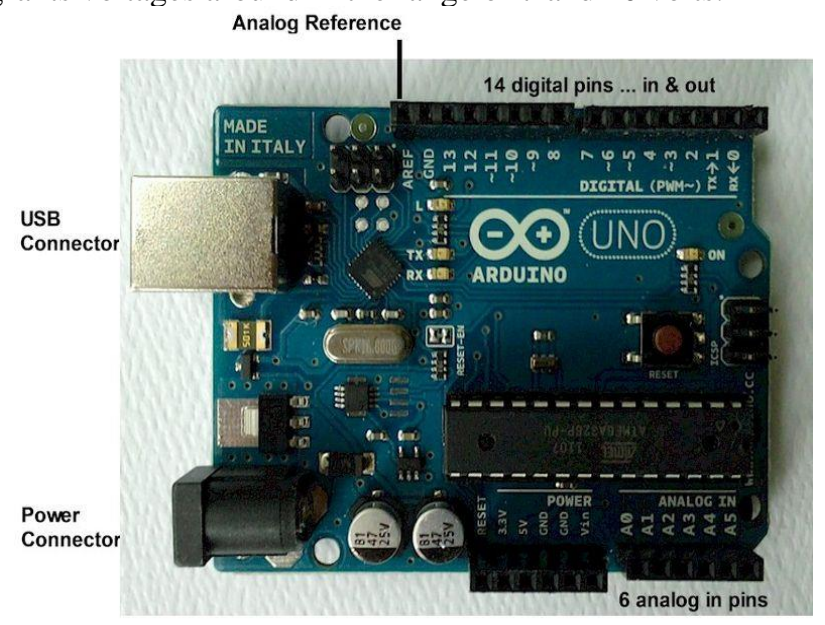

Fig. 5 Arduino UNO

\section{b) EM-18 RFID Reader}

EM-18 RFID reader is one of the regularly used RFID reader to read $125 \mathrm{KHz}$ labels. It features low price, low power intake, small form factor and simple to use. It can interrelate with a microcontroller in any one of the two sustained protocols namely TTL Serial \& Wiegand 26 as per the system proposal. $\mu$ RFID reader has a recognition pin that could be utilized to simply recognise a valid RFID card.

\section{c) RFID Tags}

Radio-frequency identification (RFID) is an expertise to records the existence of an object using radio indications. It is used for timing sporting events or resister control. RFID is not a replacement for the barcoding, but a complement for distant reading of codes. The technology is used for spontaneously recognizing a person, a bundle or an item.

\section{d) $16 \times 2 \mathrm{LCD}$}

LCD (Liquid Crystal Display) is an electrical display component and finds in a wide variety of applications. A $16 \times 2$ LCD display is very simple component and is very frequently used in numerous circuits and devices. These components are chosen over seven segments and additional multi-segment LEDs.

\section{e) DC Buzzer}

A buzzer or beeper is an alerting component, usually electrically and characteristically used in vehicles, domestic appliances such as a microwave oven, or game shows. It most commonly contains of an amount of switches or sensors linked to a controller unit that governs if and which button was pushed or a reset time has failed, and usually illuminates a light on the proper button or control panel, and sounds a attention in the form of a constant or recurrent buzzing or beeping sound. 


\section{f) Arduino Nano}

The Arduino Nano is a tiny, breadboard-friendly, and wide-ranging board created on Atmega328P, gives the same connectivity and specification of the UNO board in a reduced form factor. The Arduino Nano is functions using the Arduino (IDE) software with our Integrated Development Environment mutual to all our boards and running both off-line and on-line.

\section{g) HC-05 Bluetooth}

HC-05 component is an easy to use Bluetooth SPP (Serial Port Protocol) component, designed for translucent wireless serial linking setup. The HC-05 Bluetooth Module can be used in a Master or Slave structure, creating it a great resolution for wireless communication.

\section{h) L293D Motor Driver}

Commonly, even the simplest robot needs a motor to revolve a wheel or achieves particular action. Since motors need more current then the microcontroller pin can classically generate, you need some type of a switch which can receive a small current, strengthen it and generate a larger current, which additional drives a motor.

\section{Software Requirements \\ a) Arduino IDE}

The Arduino Integrated Development Environment holds a text console, a communication area, a text editor, a toolbar with controls for common utilities and a series of menus. It is used to write and upload programs to the arduino boards. It supports $\mathrm{C}$ and $\mathrm{C}++$ languages using some rules of code structuring. It supplies some software library which provides many common I/O procedures. The program will be converted into a text file in hexadecimal encoding that is fetched into the board.

\section{RESULT AND IMPLEMENTATION}

The proposed model is implemented and the output is shown in this section. The overall operation in the proposed model is split into two parts which are detection with locking part (fig.1) and car robot part (fig.4). The detection with locking part does the process of detection of RFID tags and giving the warning about the illegal parking with the countdown. The car robot part is used for the movement of the car using the motor driver. The locking mechanism is interfaced with the both parts.

The prototype consists of two sides where the components are fixed. The top side is shown in Fig. 6, where Arduino UNO is connected with a relay, buzzer and LCD. The Arduino is powered by a $12 \mathrm{~V}$ power supply using a portable battery. When RFID reader comes in the contact of RFID tag, a warning notification message will be displayed on the LCD which is shown in fig. 8 and fig.9 and 120 seconds countdown will get started which is programmed in the arduino. The countdown will be displayed on the LCD. After 60 seconds of the countdown, arduino will activate the relay switch.

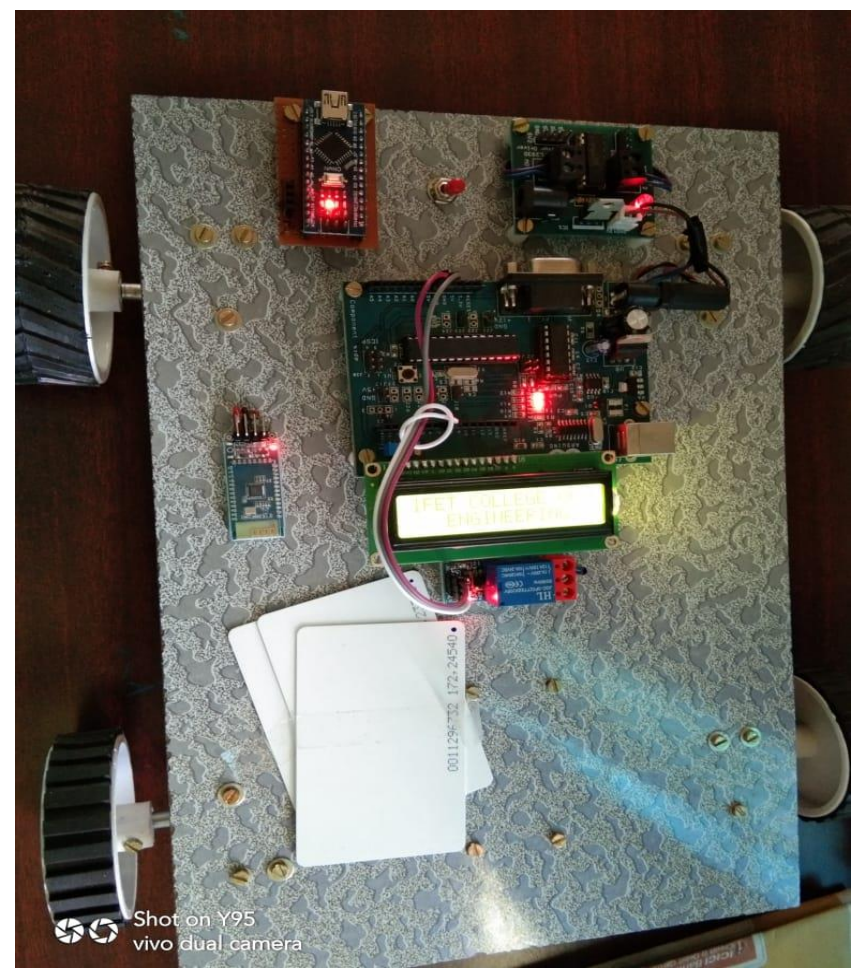

Fig. 6 Top side of the implementation

A bluetooth module is fixed which is connected with an Arduino nano for the movement of the car robot. Bluetooth module helps to connect android phone with arduino nano (refer fig.4). The car robot can be moved forward or backward using the android device controller, where arduino nano is programmed for the movement. At the bottom side which is shown in fig. 7, RFID module, portable battery and motor driver have been fixed. Once the relay switch is activated, power supply given to the motor driver will be terminated and locking done to the vehicle by this method (refer fig.10 and fig 11).

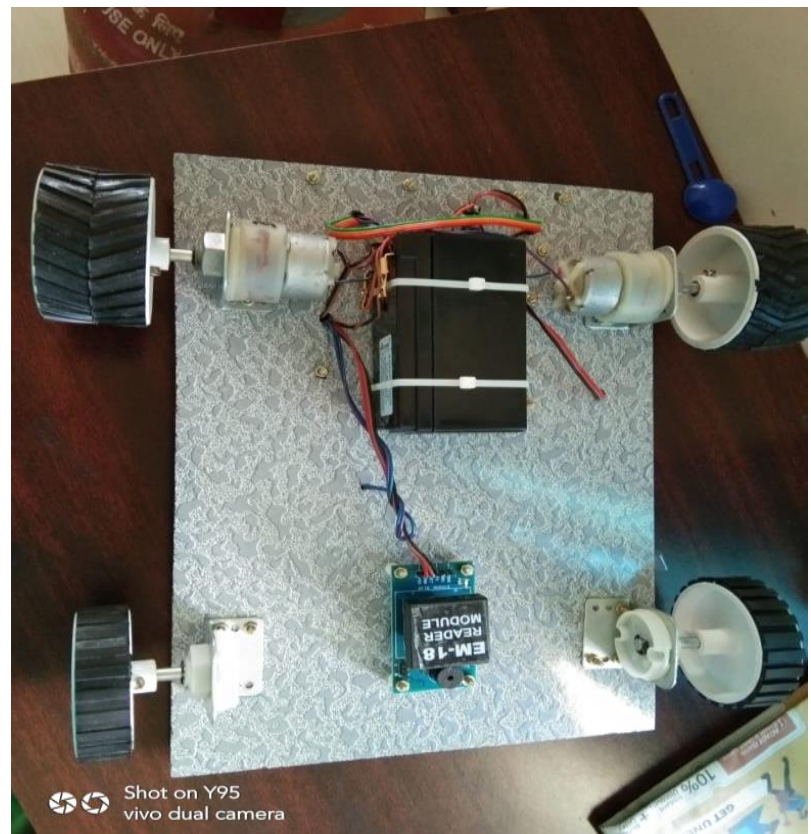

Fig. 7 Bottom side of the implementation 


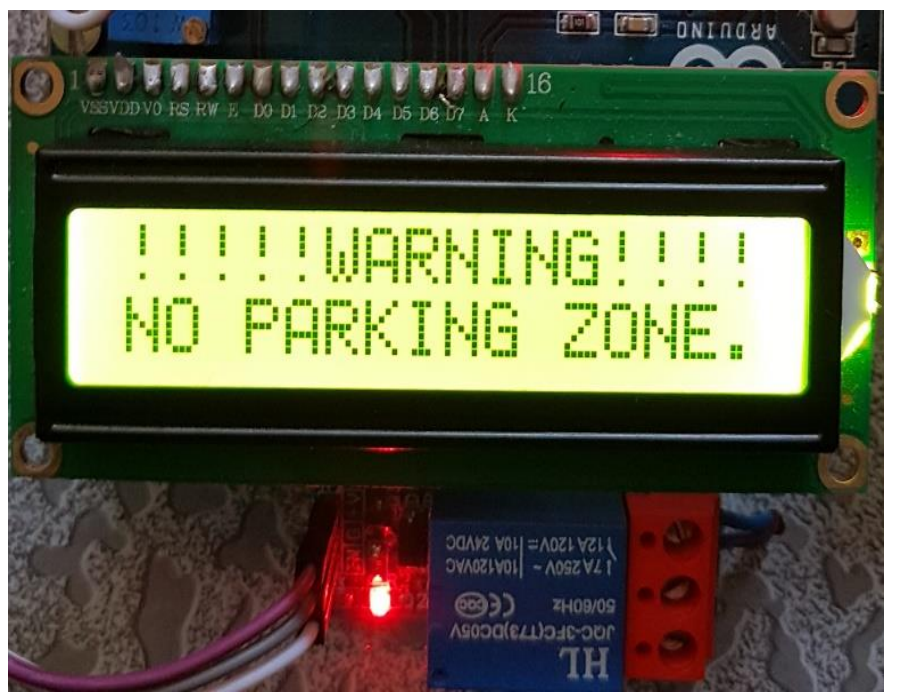

Fig. 8 Warning notification 1

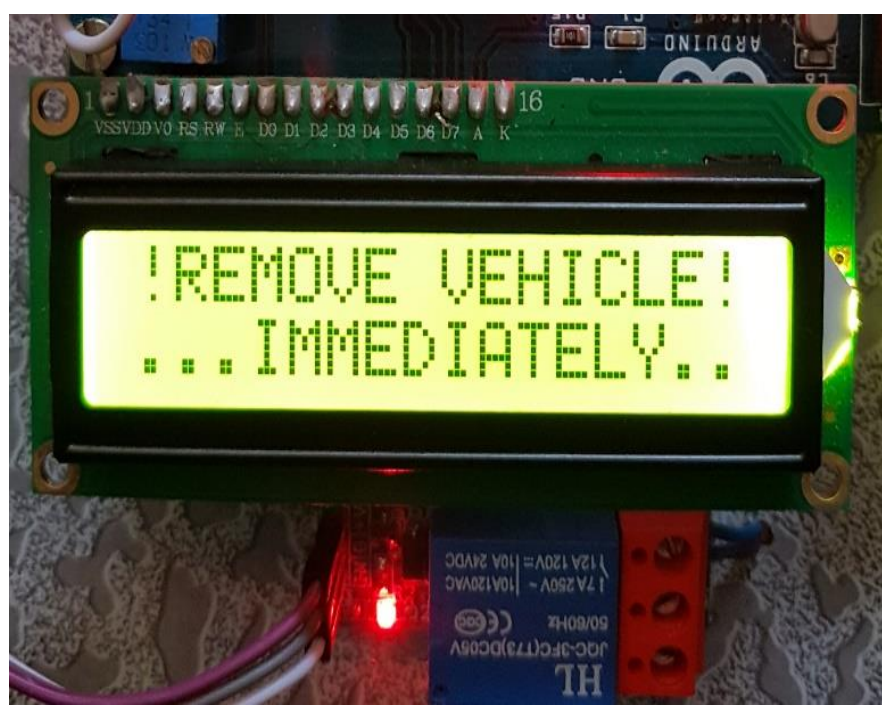

Fig. 9 Warning notification 2

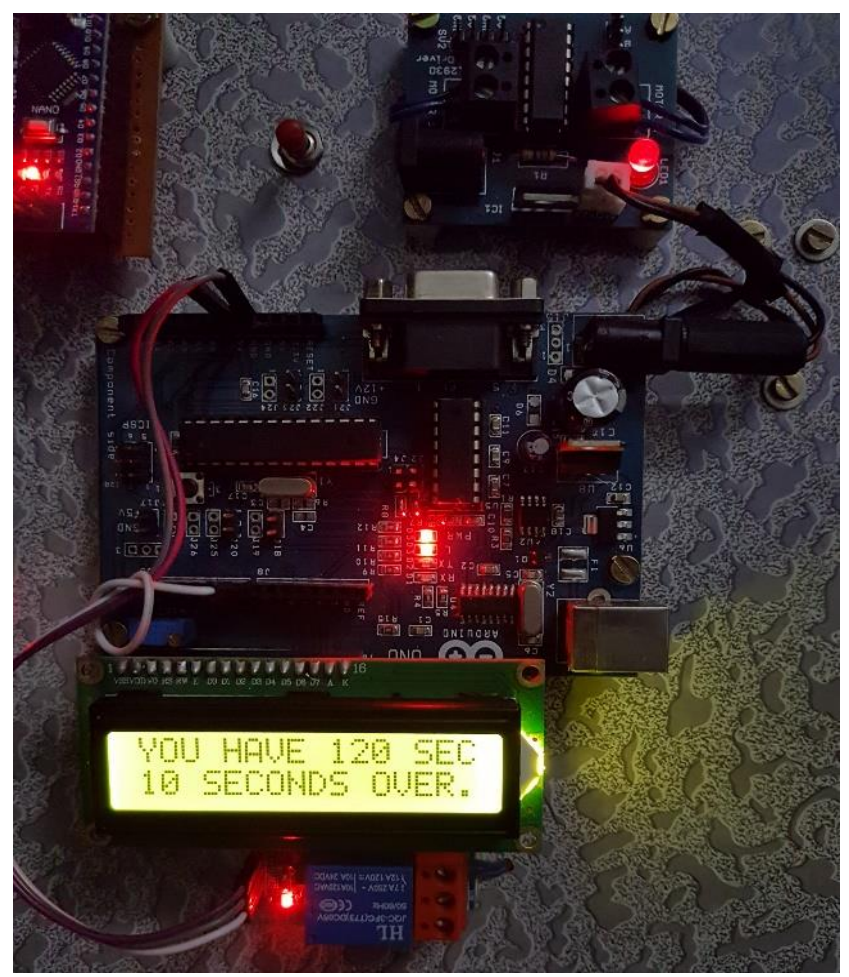

Fig. 10 Model before locking

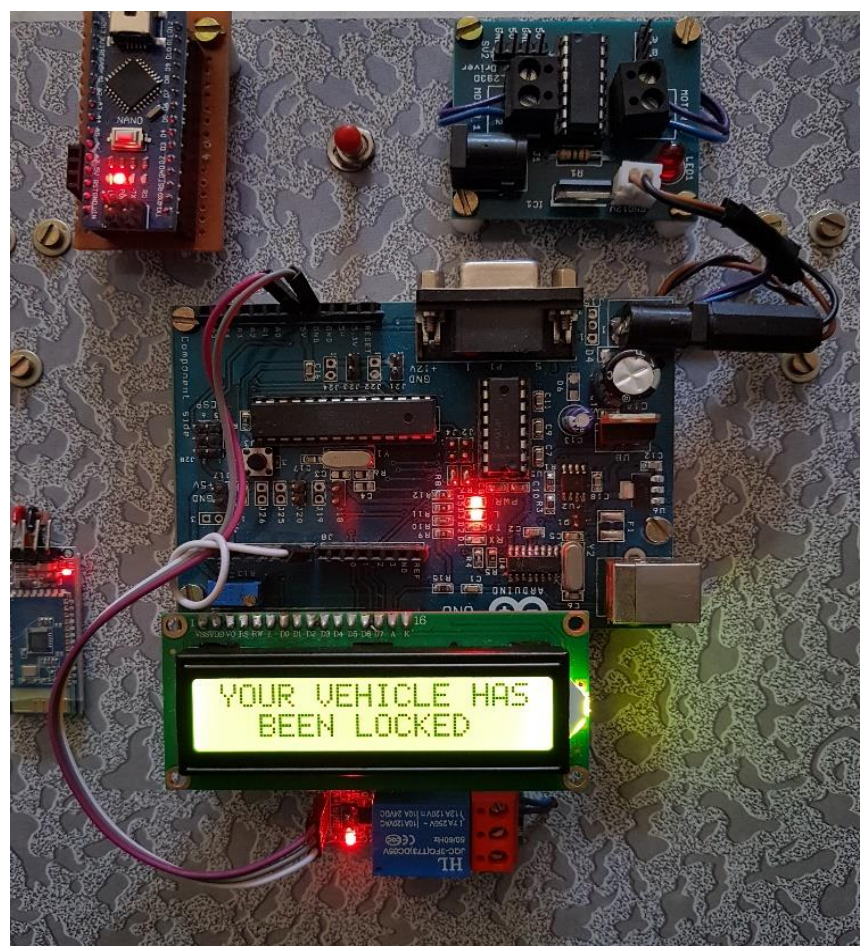

Fig.11 Model after locking

The Fig.10 represents the vehicle model before locking where the motor driver gets the power supply. After the process of no-parking detection and warning, the vehicle gets locked by terminating the power supply to the motor driver using a relay which is shown in fig. 11 respectively. This is how locking mechanism works in this proposed model.

The proposed framework can be used to avoid the illegal parking at unauthorized parking zone. By using this system, illegally parked vehicles can be locked until the traffic police arrives and collects the fine amount. This real-time application can be used in the smart city project to avoid traffic congestion and accidents.

Advantages of the proposed system:

- Real-time implementation is possible

- Lesser complex design

- High accuracy

- One time investment.

- Most important concept for upcoming smart city project.

\section{CONCLUSION}

Different advancements are utilized to recognize the unapproved vehicle parking recognition and control measures in the above review. The proposed structure will maintain a strategic distance from undesirable mishaps and traffic clogs. By utilizing this robotized framework, unlawful parking can be effectively maintained a strategic distance from without the presence of traffic police or CCTV camera, this framework won't require the physical nearness of a human at no leaving zone to make a move against wrongfully left vehicles. This framework offers another answer for the developing innovation, for example, sparing time and manual exertion and wellbeing purposes. Individuals can have an unmistakable thought of stopping status by their dashboard notice itself. This framework capacities productively and suggested for business usage.

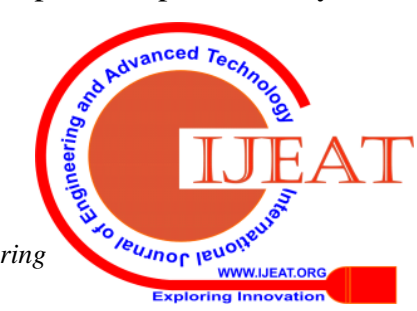




\section{FUTURE ENHANCEMENT}

In future enhancement, certain changes can be implemented. After the locking mechanism, full details about the vehicle owner and location may be sent to traffic police web server. The information can be sent using IOT device which is installed in the vehicle. Unlocking mechanism can be done through the web server itself after the concerned vehicle owner paid the fine.

\section{REFERENCES}

1. Saifa Khantasak, Nattha Jindapetch, Pakpoom Hoyingcharoen, Kanadit Chetpattananondh, Masami Ikura, " Parking Violation Detection System based on Video Processing", Proceeding of the IEEE $5^{\text {th }}$ International Conference on Smart Instrumentation, Measurement and Application, November 2018.

2. Sanam Kazi, Shirgaonkar, Ansari Nashrah, Qureshi, “ Smart Parking System to Reduce Traffic Congestion" November 2018

3. Adil Hilmani, Abderrahim Maizate and Larbi Hassouni, "Designing and Managing a Smart Parking System Using Wireless Sensor Networks" Journal of Sensor and actuator Network, June 2018.

4. Karthika.K.B, Muhilarasi.J, Priya.M, Pradheep $\mathrm{T}$ Rajan, "Automatic Unauthorized Parking Detector with SMS Notification to Owner", International Journal of Advanced Research Trends in Engineering and Technology, Vol.5, Special Issue 5, March 2018.

5. Bhenesha Shree, "Design and Implementation of Automated Car Parking System using RFID”, International Journal of Advanced Research in Computer and Communication Engineering, Vol. 6, Issue2, February 2017

6. Chihhsiong Shik, Zhaolong Liang, "The development and simulation of a smart parking guidance system", Proceedings of the IEEE International conference on applied system innovation 2017

7. Haijing Wang, Fangfang Zhang, Peng Cui, " A Parking lot induction method based on Dijkstra algorithm", 2017.

8. Ms. S. Mekala, M. AntoBennet, Melvin Jeyakumar," Automatic Vehicle Parking Indicator and Traffic Violation Detection System” Middle-East Journal of Scientific Research 24, 2016.

9. Yonatan Urman, Tamir Baruch Yampolsky and Rami Cohen, "Unsupervised Detection of Available Parking Spots", International Conference on the Science of Electrical Engineering, 2016.

10. Prof. D. J. Bonde, Rohit S. Shende, Ketan S. Gaikwad, Akshay S. Kedari,Amol U. Bhokre, "Automated Car Parking System Commanded by Android Application", International Journal of Computer Science and Information Technologies, Vol.5 (3), 2014.

11. Santhosh G.Kashid, Dr.Sanjay A.Pardeshi, "Detection and Identification of illegally Parked vehicles at no parking area" International Conference on communication and signal processing, April 2014.

12. Shen-En Shih, Wen-Hsiang Tsai, “ A Convenient Vision-Based System for Automatic Detection of Parking spaces in Indoor parking lots using wide-angle cameras", IEEE Transactions on vehicular technology, Vol. 63, no.6, July 2014

13. Liping Cheng, Chuanxi Liu, "Improved Hierarchical A-star Algorithm for Optimal Parking Path Planning of the Large Parking Lot" Proceeding of the IEEE International Conference on Information and Automation, July 2014.

14. Yanfeng Geng, Christos G.Cassandras, "A New "Smart Parking" System Based on Resource Allocation and Reservatios", IEEE Transactions on Intelligent Transportation Systems, 2013.

15. Yang Jun, "A System framework of active parking guidance and information system", WASE International Conference on Information Engineering, 2010.

16. Zhang Bin, Jiang Dalin, Wang Fang, Wan Tingting, “A Design of Parking Space Detector Based on Video Image", $9^{\text {th }}$ International Conference on Electronic Measurement and Instruments, 2009.

17. C.George Christopher, J.Vidhya, "A Survey on Unauthorized Vehicle Parking Detection and Control Measures", International Journal of Research, Vol 06 Issue 10, Sep 2019.

\section{AUTHORS PROFILE}

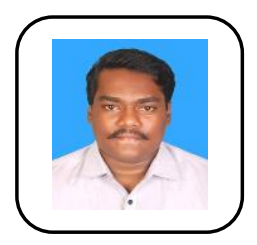

Mr. C. George Christopher has completed Bachelor of Technology in Electronics and Communication Engineering, Karunya University, Coimbatore and Pursuing Master of Engineering in Applied Electronics, IFET College of Engineering, Villupuram. He is contributing to different open source platforms. His areas of interest are Internet of Things, Application Development and Real Time Systems.

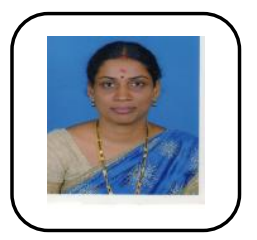

Dr. J. Vidhya has completed Bachelor of Engineering in Electronics and Communication Engineering, Bharathidasan University, Trichirapalli, Master of Technology in Electronics and Communication Engineering Pondicherry Engineering College and Doctor of Philosophy in Electronics and Communication Engineering from Pondicherry University in the area of wireless sensor networks. She has 13 years of teaching experience and is currently working with IFET college of Engineering, Villupuram. She has published 2 books, 15 journals and 6 conferences to her credit. Her research interests include Wireless communication and networks, optical communication, Antennas and Internet of things. 